\title{
Ruptured Popliteal Cyst Diagnosed by Ultrasound Before Evaluation for Deep Vein Thrombosis
}

\author{
Joon Sung Kim, MD, Seong Hoon Lim, MD, Bo Young Hong, MD, So Young Park, MD
}

Department of Rehabilitation Medicine, The Catholic University of Korea College of Medicine, Seoul, Korea

\begin{abstract}
Most popliteal cysts are asymptomatic. However, cysts may rupture, resulting in pain and swelling of the leg that could also arise from other diseases, including deep vein thrombosis, lymphedema, cellulitis, and tear of a muscle or tendon. Therefore, it is difficult to diagnose a ruptured popliteal cyst based on only a patient's history and physical examination. Musculoskeletal ultrasound has been regarded as a diagnostic tool for ruptured popliteal cyst. Here, we describe a patient who was rapidly diagnosed as ruptured popliteal cyst by ultrasonography. Therefore, ultrasound could be used to distinguish a ruptured popliteal cyst from other diseases in patients with painful swollen legs before evaluation for deep vein thrombosis.
\end{abstract}

Keywords Calf pain, Complicated popliteal cyst, Ultrasonography

\section{INTRODUCTION}

Popliteal cyst is a benign disease filled with fluid in the popliteal fossa. It occurs by distention of the semimembranosus-gastrocnemius bursa communicating with the knee joint [1]. In most cases, popliteal cyst is asymptomatic. However, popliteal cyst may rupture, resulting in calf pain and swelling similar to deep vein thrombosis (DVT) [2]. In addition, lymphedema, cellulitis, tear of a muscle

Received January 7, 2014; Accepted March 20, 2014

Corresponding author: So Young Park

Department of Rehabilitation Medicine, St. Vincent Hospital, The Catholic University of Korea College of Medicine, 93 Jungbu-daero, Paldal-gu, Suwon 442-723, Korea

Tel: +82-2-2258-2822, Fax: +82-2-2258-2825, E-mail: 1sh728@naver.com

(c) This is an open-access article distributed under the terms of the Creative Commons Attribution Non-Commercial License (http://creativecommons. org/licenses/by-nc/3.0) which permits unrestricted noncommercial use, distribution, and reproduction in any medium, provided the original work is properly cited.

Copyright (C) 2014 by Korean Academy of Rehabilitation Medicine or tendon (e.g., the medial head of the gastrocnemius [MHG] or Achilles tendon), neoplasm, and hemorrhage can cause similar symptoms. Some studies evaluated nonspecific leg symptoms, such as swelling or pain, by ultrasonography and ruptured popliteal cyst was easily detected $[3,4]$. DVT tends to be evaluated preferentially in practice in patients suffering from nonspecific leg symptoms because of the risk for pulmonary embolism. Even anticoagulation medication was administered to the patient without confirmation of blood clots in vascular lumens [2]. If the diagnostic procedure for DVT reveals no evidence of thrombosis in the deep venous system, time and cost would be wasted and unnecessary anticoagulation could result in another problem [2]. We experienced a ruptured popliteal cyst case diagnosed quickly by ultrasonography before evaluating DVT. Therefore, ultrasonography could be used to distinguish popliteal cyst from other diseases. In this article, we discussed the epidemiology, clinical features, and ultrasonographic findings of 
ruptured popliteal cyst.

\section{CASE REPORT}

A 58-year-old male patient had developed a chicken egg-sized painful lump on the left popliteal fossa two months before he visited our center. He had no obvious trauma history in the affected site. He was diagnosed with osteoarthritis in his knee joints about 5 years ago. At first, he went to an internal medicine clinic, and his doctor prescribed some oral medication. However, there was no change after he took the oral medicines. After trekking a mountain, the pain and swelling extended to his lower leg. He was referred to our outpatient clinic. His visual analogue scale was 5 and tenderness was present at the popliteal fossa and the calf. Pain was aggravated when the foot was dorsiflexed. On examination, unilateral grade 1 pitting edema accompanied by slight redness and warmth was noted in his left leg below the knee and the circumference of the left leg was $1 \mathrm{~cm}$ greater than right when measured at the calf (Fig. 1). He said the pain and swelling of the leg had been improved since the trekking. There was no motor weakness or sensory change. Weight-bearing posteroanterior plain radiography showed Kellgren-Lawrence grade 1 radiographic alterations bilaterally.

Ultrasonography revealed large hypoechoic space that was divided into two compartments behind MHG. Ul-

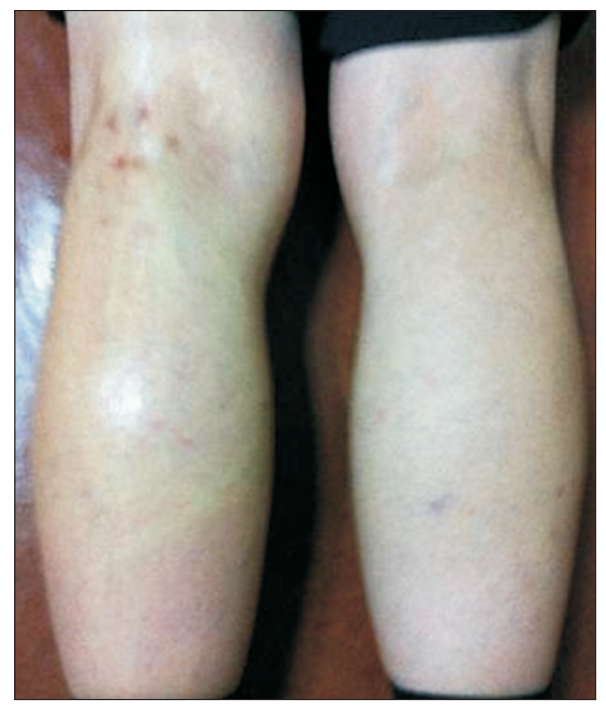

Fig. 1. Physical examination of unilateral leg swelling accompanied by slight redness and warmth was noted in the patient's left leg. trasound of the popliteal fossa showed the presence of a well-defined cyst connected knee joint. It had different component of a typical popliteal cyst: the base, the

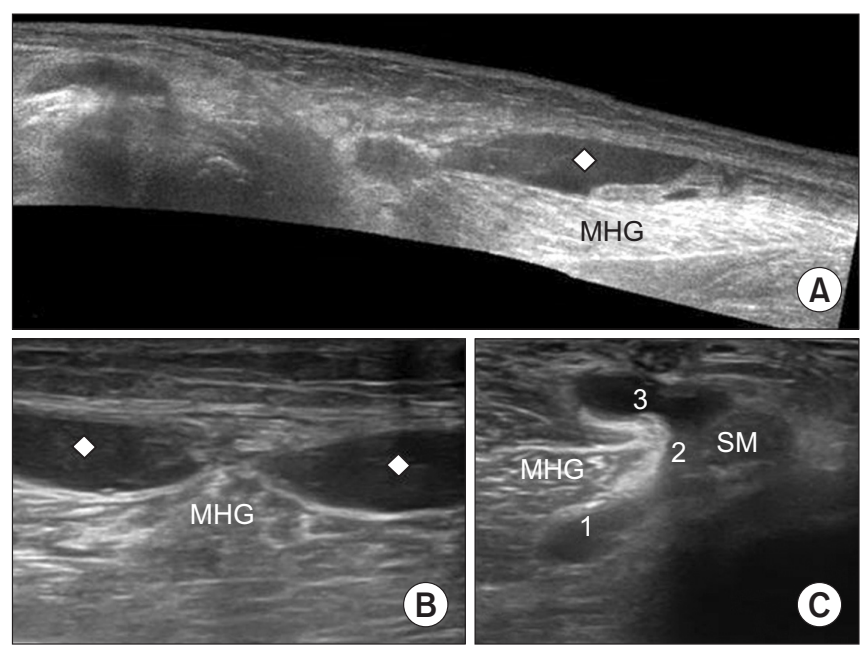

Fig. 2. Ultrasonography images. (A) Panoramic image of the longitudinal sweep of the medial aspect of calf shows fluid collection (rhomboid) behind medial head of the gastrocnemius muscle (MHG). (B) Transverse 12-5 MHz ultrasound image over the proximal medial calf shows the fluid collection separated into two compartments. (C) Transverse $12-5 \mathrm{MHz}$ ultrasound image over the popliteal fossa shows the different components of a typical popliteal cyst: the base ' 1 ', the neck ' 2 ', and the body ' 3 ' located between the tendon of the semimembranosus (SM) and the tendon of the MHG.

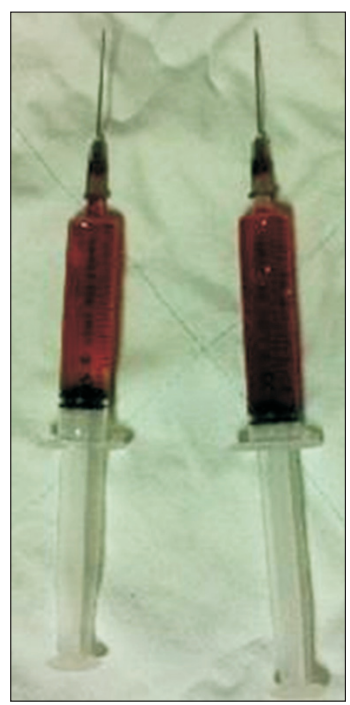

Fig. 3. Initially a $10 \mathrm{~mL}$ of dark red-colored liquid was drained from the calf. 
neck, and the body located between the tendon of the semimembranosus and the tendon of the MHG (Fig. 2). The body of the cyst was communicated with fluid collection of the calf. In addition, some joint effusion and synovial hypertrophy were seen. Initially, ultrasoundguided puncture aspiration was performed to obtain 10 $\mathrm{mL}$ of dark red-colored translucent liquid (Fig. 3). We performed the intralesional injection of corticosteroid (triamcinolone acetonide $20 \mathrm{mg}$ ) and used some nonsteroidal anti-inflammatory drug (aceclofenac). A few weeks later, he still complained of calf pain. A follow-up ultrasound revealed a fluid collection in his proximal calf. After re-aspiration of fluid under ultrasound guidance, the pain was relieved.

\section{DISCUSSION}

Popliteal cysts in adults usually communicating with the knee joint space [3] are often associated with intraarticular pathology [5]. Liao et al. [5] reported that the most common disease associated with popliteal cysts is osteoarthritis of the knee, followed by rheumatoid arthritis. Usually, cysts are not complicated and asymptomatic. In one study, prevalence of complicated cyst was $6.8 \%$, with rupture as the most common complication (50\% of complicated cysts) [6]. It is known that the popliteal cyst rupture is associated with intense physical activity [7] and inflammatory pathology (e.g., rheumatoid arthritis, gout, seronegative spondyloarthropathy, pyrophosphate arthropathy) than a degenerative one (e.g., osteoarthritis) [5]. If the cyst structure is broken, joint fluid can be spread out to adjacent tissues, such as the calf muscles. In that case, patients suffer symptoms, such as a painful swollen leg with positive Homan's sign which might lead to a misdiagnosis as DVT [2]. Sato et al. [3] reported DVT was the most common cause of swollen leg (44.8\%), followed by idiopathic (31.2\%), lymphedema (12.8\%), a ruptured popliteal cyst (2.4\%), and inflammation (2.4\%). Volteas et al. [8] also reported that the incidence of a ruptured popliteal cyst in patients with symptom of DVT was rare. Although a ruptured popliteal cyst is rare, distinguishing it from DVT is important because their treatments and clinical features are substantially different. DVT may lead to pulmonary embolism, whereas ruptured popliteal cysts rarely cause compartment syndrome requiring fasciotomy [9]. In addition, use of anticoagula- tion medication increases the risk of compartment syndrome by causing bleeding from the cyst [2]. Meanwhile, several diseases should also be excluded since nearly the same symptoms may appear in cellulitis, lymphedema, and the tear of a medial head of the gastrocnemius or Achilles tendon.

There are two main modalities for diagnosis of ruptured popliteal cysts: magnetic resonance imaging (MRI) and musculoskeletal ultrasound. Although MRI is the most accurate tool for imaging soft tissue abnormalities, ultrasound is preferred over MRI because it is less expensive and more convenient than MRI. Furthermore, it is possible to confirm the diagnosis and relieve symptoms by ultrasound-guided cyst aspiration.

From ultrasonographic findings of ruptured popliteal cyst, Sato et al. [3] reported a large anechoic or hypoechoic space located in the back of the calf muscles. However, such features could be seen in other diseases. Watts and Bretland [10] reported necrotizing fasciitis showing a fluid collection behind the knee and calf muscles in ultrasonography. Unlike most popliteal cysts in adults, the popliteal fluid collection in this case did not communicate with knee joints. Therefore, it is necessary to ensure not only that the calf fluid collection and the popliteal fluid collection are connected, but also that the popliteal fluid collection is a popliteal cyst exactly. Ward et al. [1] also reported a fluid collection between the tendon of semimembranosus and the MHG was a definite finding of a popliteal cyst. On the other hand, other injury, such as a tear of the Achilles tendon and MHG, could also be confirmed by ultrasonography [4].

In our case, painful leg swelling occurred in a patient who had a lump on his popliteal fossa. Although there were various possible causes of this symptom, a ruptured popliteal cyst was diagnosed quickly and accurately by the musculoskeletal ultrasonography. We suggest that confirmation of clinical diagnosis with musculoskeletal ultrasound, preferentially in patients suffering from a painful swollen leg, may enable the rapid diagnosis and prevention of unnecessary diagnostic or therapeutic procedures.

\section{CONFLICT OF INTEREST}

No potential conflict of interest relevant to this article was reported. 


\section{REFERENCES}

1. Ward EE, Jacobson JA, Fessell DP, Hayes CW, van Holsbeeck M. Sonographic detection of Baker's cysts: comparison with MR imaging. AJR Am J Roentgenol 2001;176:373-80.

2. Dunlop D, Parker PJ, Keating JF. Ruptured Baker's cyst causing posterior compartment syndrome. Injury 1997;28:561-2.

3. Sato O, Kondoh K, Iyori K, Kimura H. Midcalf ultrasonography for the diagnosis of ruptured Baker's cysts. Surg Today 2001;31:410-3.

4. Kane D, Balint PV, Gibney R, Bresnihan B, Sturrock RD. Differential diagnosis of calf pain with musculoskeletal ultrasound imaging. Ann Rheum Dis 2004;63:11-4.

5. Liao ST, Chiou CS, Chang CC. Pathology associated to the Baker's cysts: a musculoskeletal ultrasound study.
Clin Rheumatol 2010;29:1043-7.

6. Molla Olmos E, Marti-Bonmati L, Llombart Ais R, Dosda Munoz R. Prevalence and characteristics of complications of Baker cysts by MRI. Rev Clin Esp 2001; 201:179-83.

7. Romem A, Shimony A, Horowitz S, Horowitz J. Popliteal cyst rupture due to unusual physical stress. Harefuah 2007;146:653-4, 736.

8. Volteas SK, Labropoulos N, Leon M, Kalodiki E, Nicolaides AN. Incidence of ruptured Baker's cyst among patients with symptoms of deep vein thrombosis. $\mathrm{Br} \mathrm{J}$ Surg 1997;84:342.

9. Klovning J, Beadle T. Compartment syndrome secondary to spontaneous rupture of a Baker's cyst. J La State Med Soc 2007;159:43-4.

10. Watts RA, Bretland PM. Necrotizing fasciitis mimicking a ruptured popliteal cyst. J R Soc Med 1990;83:52-3. 